Review

\title{
Neuroprotective Strategies in Glaucoma - Translation to Clinical Trials
}

\author{
Clarissa E. H. Fang ${ }^{1}$, Li Guo ${ }^{1}$, Daniel Hill ${ }^{1}$, Timothy E. Yap ${ }^{2}$, M. Francesca Cordeiro ${ }^{1,2, *}$
}

1. Glaucoma \& Retinal Neurodegeneration Research Group, Institute of Ophthalmology, University College London, London, EC1V 9EL, United Kingdom; E-mails: fangclarissa@gmail.com; I.guo@ucl.ac.uk; d.hill.13@ucl.ac.uk; m.cordeiro@ucl.ac.uk

2. Western Eye Hospital, Imperial College Healthcare NHS Trust, London, United Kingdom; E-mail: timothyedward.yap@nhs.net

* Correspondence: M. Francesca Cordeiro; E-Mail: m.cordeiro@ucl.ac.uk

Academic Editor: Ping K. Yip

Special Issue: Neuroprotection, Neuroregeneration and Neuroplasticity

OBM Neurobiology

2020, volume 4, issue 2

doi:10.21926/obm.neurobiol.2002062
Received: April 16, 2020

Accepted: June 10, 2020

Published: June 15, 2020

\begin{abstract}
Neuroprotection in glaucoma is any medical treatment by which decline in visual function can be slowed or prevented by supporting the health and survival of neural cells, independent of lowering of intraocular pressure (IOP). This is achieved by targeting mechanisms to inhibit or delay retinal ganglion cell death and promote cell survival pathways. Despite demonstrating promising results in preclinical trials, many neuroprotective strategies have failed to show success in subsequent clinical trials. Of the clinical trials performed, many have been hampered by slow disease progression and questions surrounding biomarker sensitivity. Adaptive clinical trial design, enriched populations and the use of state-of-the-art clinical endpoints are required to improve assessment of therapeutic efficacy. We review the neuroprotective strategies in glaucoma that have been investigated in clinical trials, and appraise experimental designs, the strength of the original hypotheses and preceding work to examine why so few candidates have successfully translated into clinical research.
\end{abstract}

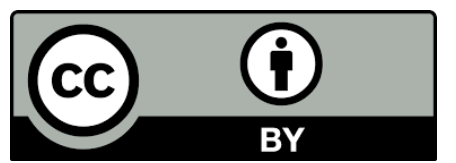

(C) 2020 by the author. This is an open access article distributed under the conditions of the Creative Commons by Attribution License, which permits unrestricted use, distribution, and reproduction in any medium or format, provided the original work is correctly cited. 


\section{Keywords}

Glaucoma; neuroprotection; translation

\section{Introduction}

Currently, the only clinically-approved treatments for glaucoma involve the reduction of intraocular pressure (IOP) despite much research into the development of neuroprotective strategies. Neuroprotection in glaucoma is understood as methods aimed at reducing or preventing loss of visual function, via an IOP-independent mechanism [1]. Despite numerous demonstrations of successful neuroprotective agents in experimental glaucoma, very few of these treatments have reached clinical trials. Of the treatments that have reached clinical trials, the results have often not reflected the preclinical research. Whether this is simply another example of the 'reproducibility crisis' [2] or in fact a failure of longitudinal study design or clinical endpoints that are unfit for purpose, is still to be decided.

Recent advances have suggested a broad range of potential molecular mechanisms of RGC death in glaucoma [3-5]. These include glutamate excitotoxicity [6, 7], mitochondrial dysfunction and oxidative stress [6-9], and the dysregulation and obstruction of neurotrophins such as nerve growth factor (NGF) and brain derived neurotrophic factor (BDNF) $[6,7,10,11]$. As understanding of glaucomatous pathology remains incomplete, learning from unsuccessful clinical trials is challenging [12]. This review article details the latest neuroprotective strategies in glaucoma that have reached clinical trials (Table 1, Figure 1), as well as discussing the strengths and limitations of the trials investigating their efficacy.

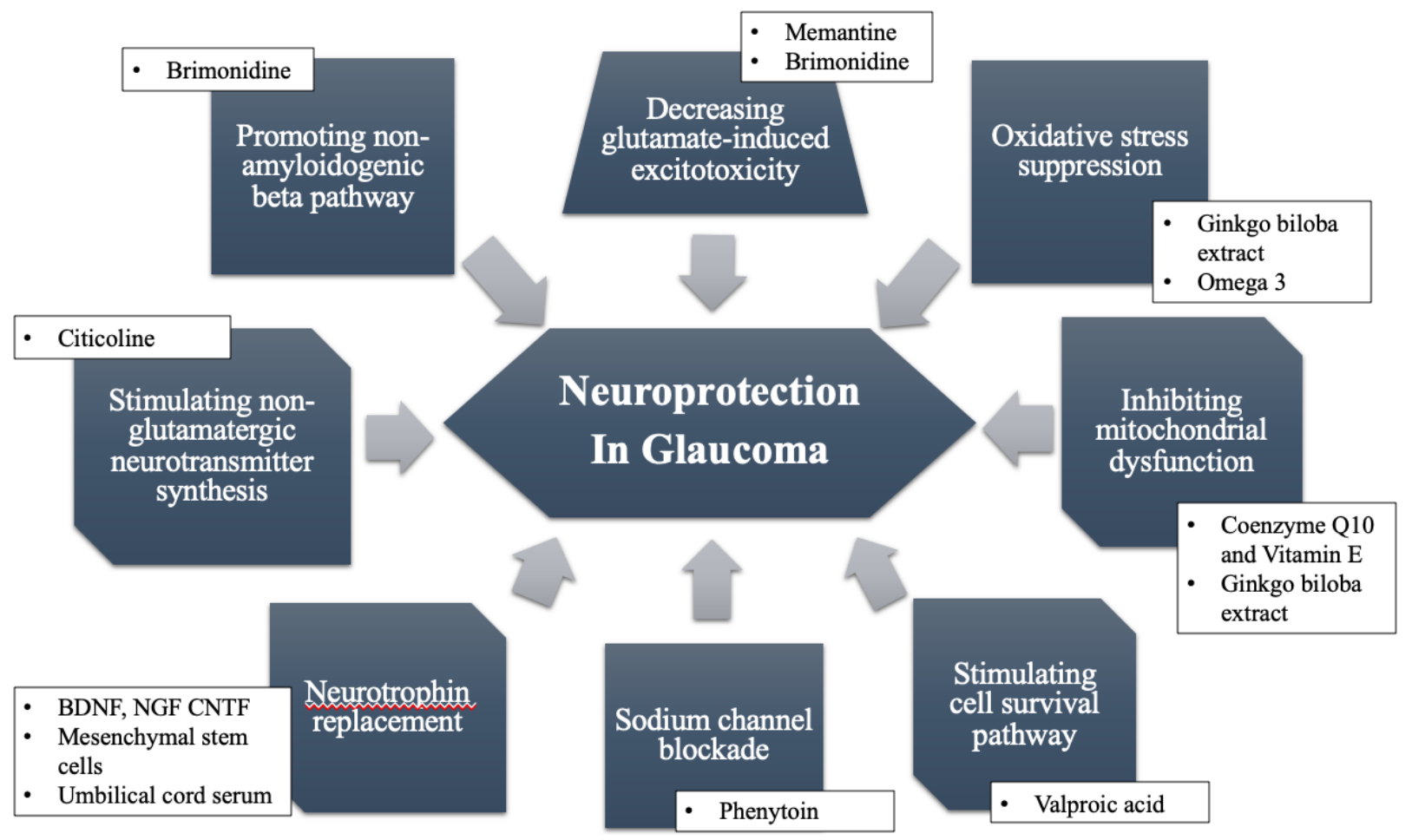

Figure 1 Neuroprotective strategies in glaucoma translated to clinical trials. 
Table 1 Neuroprotective agents for glaucoma treatment into clinical trials.

\begin{tabular}{|c|c|c|c|c|c|}
\hline Agent & Class & Mechanism & Administration & Level of Evidence* & References \\
\hline BDNF, NGF and CNTF & Neurotropic factors & Neurotrophin replacement & Topical & IIIB & {$[4,6,11,13-20$} \\
\hline $\begin{array}{l}\text { Ginkgo biloba } \\
\text { extract }\end{array}$ & Antioxidant & $\begin{array}{l}\text { Oxidative stress suppression } \\
\text { Inhibiting mitochondrial } \\
\text { dysfunction }\end{array}$ & Oral & $\mathrm{IB}$ & {$[21-28]$} \\
\hline $\begin{array}{l}\text { Coenzyme Q10 and } \\
\text { Vitamin E }\end{array}$ & Antioxidant & $\begin{array}{l}\text { Inhibiting mitochondrial } \\
\text { dysfunction }\end{array}$ & Topical & IB & [29-31] \\
\hline Omega 3 & Antioxidant & Oxidative stress suppression & Oral & IB & {$[32-37]$} \\
\hline Memantine & $\begin{array}{l}\text { NMDA receptor } \\
\text { antagonist }\end{array}$ & $\begin{array}{l}\text { Decreasing glutamate-induced } \\
\text { excitotoxicity }\end{array}$ & Oral & $\mathrm{IB}$ & {$[38-44]$} \\
\hline Brimonidine & Alpha 2 agonists & $\begin{array}{l}\text { Decreasing glutamate-induced } \\
\text { excitotoxicity Promoting non- } \\
\text { amyloidogenic beta pathway }\end{array}$ & Topical & $\mathrm{IA}$ & {$[44-55]$} \\
\hline Citicoline & & $\begin{array}{l}\text { Stimulating non-glutamatergic } \\
\text { neurotransmitter synthesis }\end{array}$ & Topical & IB & {$[56-66]$} \\
\hline Valproic acid & Antiepileptic drug & Stimulating cell survival pathway & Oral & IIB & {$[67-71]$} \\
\hline Phenytoin & Antiepileptic drug & Sodium channel blockade & Oral & IIB & {$[72-75]$} \\
\hline $\begin{array}{l}\text { Umbilical cord } \\
\text { serum }\end{array}$ & & Neurotrophin replacement & Topical, implant & IV & {$[76-79]$} \\
\hline $\begin{array}{l}\text { Mesenchymal stem } \\
\text { cells }\end{array}$ & & Neurotrophin replacement & $\begin{array}{l}\text { Retrobulbar, subtenon, } \\
\text { intravenous, } \\
\text { intravitreal and } \\
\text { intraocular injections }\end{array}$ & IV & {$[80-83]$} \\
\hline
\end{tabular}

Abbreviations: N-methyl-D-aspartate (NMDA), brain derived neurotrophic factor (BDNF), nerve growth factor (NGF), ciliary neurotrophic factor (CNTF) *OCEBM Levels of Evidence Working Group. "The Oxford Levels of Evidence 2".

Oxford Centre for Evidence-Based Medicine. https://www.cebm.net/index.aspx?o=5653 


\section{Neurotropic Factors - BDNF, NGF, and CNTF}

Neurotrophic factors have been shown to play a vital role in experimental models of glaucoma by supporting the growth [6], survival and repair of neurons, and inhibiting RGC apoptosis [13]. In comparison to NGF, more evidence supports the efficacy of BDNF for RGC survival [13]. In preclinical studies, upregulation of brain-derived neurotrophic factor (BDNF) using gene therapy was shown to be neuroprotective of RGCs in rat ocular hypertension models [11, 14, 15]. A similar effect was also seen using topical nerve growth factor (NGF) [16-18]. Over-expression of CNTF in an experimental rat model showed a significant protective effect on RGCs [19].

In human studies, Oddone et al. reported a case-control study showing reduced levels of BDNF and NGF in early and moderate, but not advanced, glaucoma patients [20], with potential for BDNF and NGF to be early biomarkers of glaucoma [20]. In a trial of 3 patients with advanced glaucoma, topical NGF has been shown to improve visual function on pattern electroretinography (PERG) and visual evoked potentials [18]. In addition, Neurotech Pharmaceuticals (Cumberland, Rhode Island, USA) have developed an implant (NT-501) which consists of encapsulated human cells genetically modified to secrete ciliary neurotrophic factor (CNTF). Phase I clinical trials for NT-501 in glaucoma patients demonstrated no serious adverse events (NCT01408472) and phase II clinical trials are currently in progress (NCT02862938)[4].

\section{Antioxidants- Gingko Biloba Extract, Coenzyme Q10 and Vitamin E, and Omega 3}

\subsection{Gingko Biloba Extract}

Gingko biloba extract (GBE) is known to have antioxidant properties via stabilisation of mitochondria that have entered the apoptotic pathway [21], with neuroprotective actions shown in rat models of glaucoma [22]. A double-masked, randomized, placebo-controlled clinical trial (RCT) of 30 participants with normal tension glaucoma demonstrated that GBE can increase ocular blood flow as measured by Heidelberg retina flowmeter [23]. Lee et al. published a retrospective study reporting the reduction of visual field loss with $80 \mathrm{mg}$ of GBE administered orally twice daily over 4 years [24]. In support, another retrospective study by Shim et al. showed improvement in visual fields in those taking $80 \mathrm{mg}$ GBE twice daily for at least 12 months [25]. A randomized controlled trial by Quaranta et al. also showed improvement of visual field parameters in those with visual field defects after 1 month of GBE treatment [26]. Whether these are truly regenerative effects, increases in retinal sensitivity, or a learning effect is unclear. However, GBE showed no effect on visual field or contrast sensitivity in patients with newly diagnosed normal tension glaucoma in another randomized clinical trial [27]. The effect of antioxidants on glaucoma progression has been studied in a phase III randomised trial (NCT01544192) comparing GBE, $\alpha$-tocopherol and placebo, with results still to be reported [28].

\subsection{Coenzyme Q10 With Vitamin E}

Topical coenzyme Q10 with Vitamin E has mitochondrial-targeted antioxidant properties. Topical coenzyme Q10 has been shown to reduce RGC loss and apoptosis compared to controls in a rat model of ocular hypertension [29]. A randomised clinical trial of 43 patients with primary open angle glaucoma demonstrated improvements in electrophysiological measurements of inner retinal 
function after 12 months of coenzyme Q10 with Vitamin E treatment (as is commercially available) [30]. A randomised double masked placebo-controlled clinical trial with topical coenzyme Q10 and vitamin $\mathrm{E}$ administered to participants with primary open angle glaucoma is currently in progress (NCT03611530)[31].

\subsection{Omega 3}

Dietary omega 3 is an antioxidant supplement, with pre-clinical studies having demonstrated neuroprotective properties [32] and increases in aqueous outflow leading to a lowering of IOP [33]. The majority of studies regarding dietary omega 3 are observational and suggest that a higher glaucoma risk is associated with a lack of dietary omega 3 [34, 35]. A pooled analysis from two double-masked, placebo-controlled randomized trials has shown a reduction of IOP in normotensive adults taking oral omega 3 for three months [36]. In a randomised placebo controlled study in patients with controlled IOP (less than $21 \mathrm{mmHg}$ ) by Garcia-Medina et al., oral omega 3 was not shown to be beneficial in glaucoma progression [37], with no significant difference in visual field or structural measurements after a follow-up period of two years [37].

\section{Glutamate-Induced Excitotoxicity}

\subsection{Memantine}

Memantine is a non-competitive glutamatergic NMDA ( $\mathrm{N}$-methyl-D-aspartate) receptor antagonist thought to improve cognitive function in moderate to severe Alzheimer's disease in combination with either acetylcholinesterase inhibitors or vitamin D [38]. When applied in animal models of glaucoma, memantine produced promising results in the reduction of RGC apoptosis rates [39-43]. In order to provide a topically applied sustained-release preparation that is able to deliver therapeutic concentrations to the retina, a nanoparticle delivery system has been investigated in vitro and in vivo, thus avoiding systemic side effects [41]. The results of this demonstrated RGC protection in a rat ocular hypertension model.

Orally administered memantine was tested in two large-scale, phase III, multicentre, randomised, placebo-controlled trials over 4 years, conducted 1 year apart [44]. Glaucoma progression was measured with standard automated perimetry (SAP), frequency doubling technology (FDT), and stereoscopic optic disc photographs. There was no significant benefit of memantine over placebo in the progression of open angle glaucoma. Barriers to reliably detecting significant results in this trial have been proposed including: IOP lowering therapies were left to the discretion of investigators rather than by a strict protocol, the inclusion of a wide range of disease severity including significantly advanced disease, variable criteria for the definition of low tension glaucoma patients, exclusion of subjects as soon as they showed visual field progression.

\subsection{Brimonidine}

Brimonidine is an alpha-2 adrenergic agonist, used topically in patients with glaucoma to lower IOP by reducing aqueous production and increasing uveoscleral outflow [45]. Brimonidine is thought to have a dual mechanism of action in glaucoma, as suggested by IOP-independent neuroprotective effects in experimental models of glaucoma [46]. It is proposed that this is accomplished via modulation of glutamate transporters and NMDA receptors [47, 48], and 
promoting the non-amyloidogenic beta pathway [46]. In a small clinical study involving patients with POAG, those that were treated with brimonidine over the course of 1 year demonstrated reduced loss of retinal nerve fibre layer thickness (independent of IOP reduction) compared to patients treated with timolol [49]. In another study comparing brimonidine with timolol, brimonidine appeared to improve contrast sensitivity after 3 months of treatment, a finding which was also independent of IOP reduction [50]. In a RCT comparing topical brimonidine to argon laser trabeculoplasty (ALT) in patients with POAG, brimonidine significantly reduced visual field deterioration over 18 months despite the IOP reduction having been less than that of ALT [51].

The Low-Pressure Glaucoma Treatment Study (LoGTS), showed that topical brimonidine twice daily preserved visual field to a greater extent than topical timolol in low tension glaucoma patients, despite similar IOP-lowering effects after a follow-up period of 4 years [52, 53]. Although this would support the neuroprotective actions of brimonidine, the high dropout in the brimonidine group (28.3\%) compared to the timolol group (11.4\%) must be considered. An attrition bias causing progressing patients in the brimonidine group to leave the study may otherwise explain the results. Alternatively, the neuroprotective effects of brimonidine may in some way have been related to those who did not have ocular allergy. Furthermore, the IOP target in this study was a reduction of $\geq 20 \%$ which was achieved by only $44 \%$ of brimonidine group and $39 \%$ of timolol group. This could suggest that the subjects were undertreated or had poor compliance with drops. Other factors in the interpretation of the results of this study include the possible adverse systemic hypotensive effects of timolol on optic nerve perfusion, and the differences in diurnal variation [54]. Clinical evidence still exists to refute these findings, albeit with similar issues surrounding the withdrawal rates and also low prevalence of visual field progression [55].

\section{Citicoline}

Citicoline is an endogenous compound that is thought to be protective of damaged neurons by altering non-glutamatergic neurotransmitter synthesis. It is thought to accomplish this via influencing the synthesis of phosphatidylcholine, a cell membrane phospholipid [56]. Intraperitoneal administration of citicoline was shown to increase retinal dopamine concentrations in rabbits [57]. Citicoline was also demonstrated to decrease neuron damage in a rat optic nerve crush model [58] and model of kainic acid-induced retinal damage [56]. In the same model, a reduction in concentration of apoptotic proteins such as mitogen-activated protein kinase was found [59]. Citicoline was shown to support regeneration of RGCs in a tissue culture of mouse retina [60]. In patients, intramuscular citicoline appeared to be beneficial for glaucoma, and visual field progression was shown to slow in 9 out of 11 patients following 6-monthly intramuscular citicoline administration over 10 years, compared to the control group. [61, 62] Oral administration of citicoline was also reported to improve visual evoked potentials in 13 out of 21 patients with glaucoma [63]. In a study of 41 patients with POAG, 2 years of oral citicoline was reported to decrease the rate of visual field loss [64]. Using pattern electroretinography (PERG), 16 patients with progressive open angle glaucoma showed RGC function improvement after treatment with topical citicoline three times daily for two months, but regressed after one month of stopping treatment [65]. Similarly, a randomized clinical trial showed topical citicoline could improve PERG and visual evoked potentials after being administered three times daily for 4 months but the effect stopped 
two months later [66], suggesting a lack of permanent regenerative effects, or the need for continued citicoline treatment to prevent retinal functional deterioration.

\section{Antiepileptics Drugs - Valproic Acid and Phenytoin}

\subsection{Valproic Acid}

Valproic acid, a commonly used antiepileptic and mood stabiliser, has been shown to improve RGC survival in cell culture and in rats with optic nerve crush injury, by stimulating BDNFtrkB(tropomyosin-related kinase B) signalling pathway and inhibiting histone deacetylase [67-69]. Preliminary clinical results for use in retinitis pigmentosa demonstrate some short-term benefits in terms of visual acuity and visual field preservation, however follow-up in the study was only 6 months in duration.[70]. Oral valproate has been reported to significantly improve visual acuity when taken for 3 months, and the effect lasted for 9 months after cessation in advanced glaucoma patients. However, in this unmasked randomized clinical trial, there was no improvement in visual field or electroretinography (ERG) [71]. Given this trial was unmasked to the patients, an interesting confounder in mood improvement may have otherwise explained the beneficial effects of valproic acid [71].

\subsection{Phenytoin}

The anti-epileptic drug, phenytoin, has been shown to exhibit neuroprotective effects on RGC density and decrease axon loss in the optic nerve in a rat model of glaucoma. This neuroprotection is thought to be the result of sodium channel blockade [72]. In a study conducted in the 1970s, phenytoin showed neuroprotective effects on retinal degeneration in patients with glaucoma [73]. In that cohort of 17 patients, 11 showed improvement of visual fields after two months of treatment. Phenytoin has now been used in the treatment of optic neuritis in a phase II RCT, in which it demonstrated a reduction in the loss of retinal nerve fibre layer thickness [74]. In glaucoma, however, there have been fewer advancements using phenytoin. Notably, a cohort study of orally administered phenytoin in glaucoma patients in Israel has yet to publish their results (NCT00739154) [75].

\section{Umbilical Cord Serum}

Umbilical cord serum is known for its high content of neurotrophic growth factors [76]. Topical application of cord serum has been used for the treatment of severe ocular surface disease $[77,78]$. A case report by Campos et al. described improvement in visual fields in two patients with primary open angle glaucoma after topical administration of cord serum over two months, however the improvement of their co-existing ocular surface disease may well have improved their visual field test performance. The same research group are currently carrying out a non-randomised clinical study with 4 month follow-up using topical cord serum in glaucoma patients (NCT03609125) [79].

\section{Mesenchymal Stem Cells}

Mesenchymal stem cells can proliferate and differentiate into glial cells and neurons, as well as secrete BDNF [80]. Intravitreal administration of mesenchymal stem cells has demonstrated an 
increase in RGC survival in a rat model of glaucoma [81]. The use of mesenchymal stem cells for optic nerve and retinal conditions has been assessed by the Stem Cell Ophthalmology Treatment Study (SCOTS), an open-label non-randomized efficacy study (NCT01920867) [82]. Routes of administration include retrobulbar, subtenon, intravenous, intravitreal and intraocular injection with vitrectomy. Early reports have shown positive results for Leber's hereditary optic neuropathy and optic neuritis. The SCOTS study is currently enrolling participants with glaucoma. Presently, there are two phase I clinical trials using mesenchymal stem cells in glaucoma patients; one is being conducted in Brazil, in patients with advanced glaucoma (NCT02330978), and the other in Russia (NCT02144103)[83]. The outcomes are awaited.

\section{Future of Neuroprotection}

There are many barriers to successful translation of glaucoma treatment into clinical practice (Figure 2). The main factors amongst these are inherent in the delivery of the drug to the target tissue, and the biomarkers available to monitor therapeutic response.

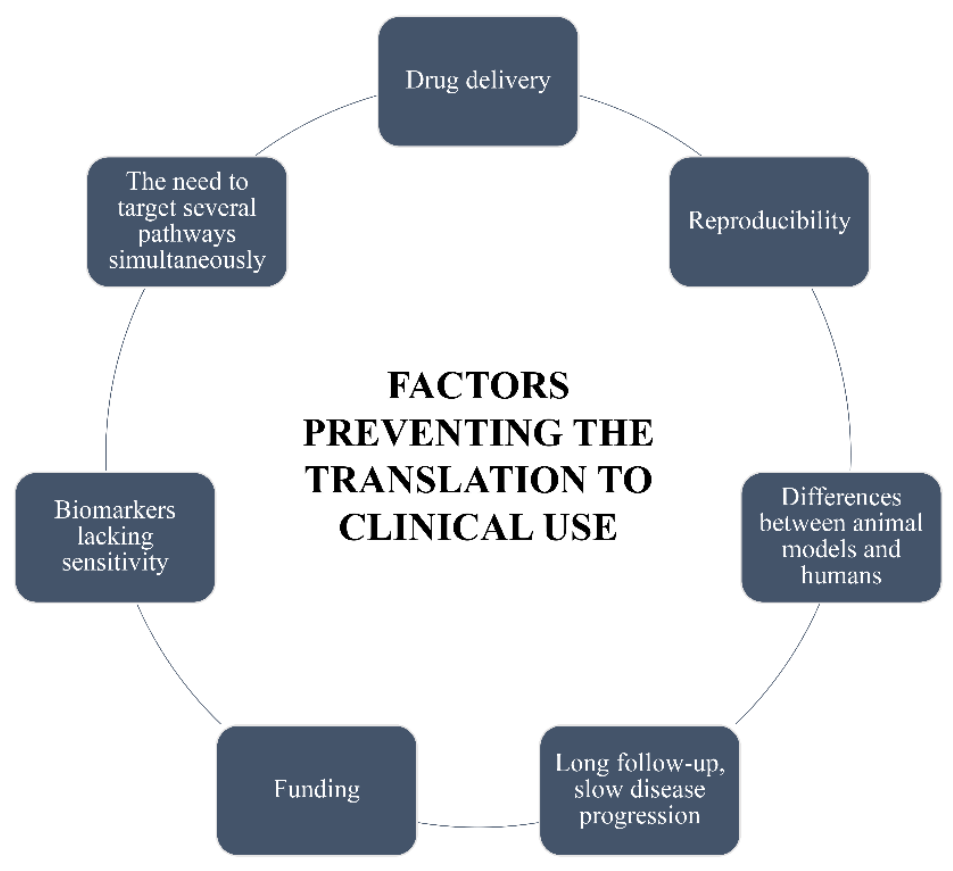

Figure 2 Factors preventing the translation to clinical use.

Besides having a therapeutic effect, successful novel treatments require sufficient bioavailability with suitable dosing supporting compliance from the patient. This is being tackled by using novel formulations and routes of delivery, whilst also exploring new classes of treatment such as neurotrophic factors and stem cells. In terms of detecting therapeutic effect, other conditions such as Alzheimer's disease, Parkinson's disease, multiple sclerosis and ageing itself also demonstrate retinal neurodegeneration and can confuse the clinical picture [84, 85]. Other confounders in glaucoma can also include lifestyle factors, ethnicity and systemic medications.

In line with ethical regulations, trials are carried out with patients already receiving IOP-lowering treatment, with the purpose of diminishing the remaining glaucoma progression below that achieved by IOP lowering treatment alone [86]. Of the clinical trials mentioned in the manuscript, 
there is paucity of information on potential interactions of current or previous medications with the novel agents. It may be unlikely that novel agents will interact with traditional IOP lowering agents. It is thought that the traditional IOP lowering medications may also have non IOP lowering neuroprotective effects, such as in the case of the alpha agonists brimonidine which have neuroprotective features in addition to lowering IOP [52]. There are purported alternative neuroprotective mechanisms such as the anti-apoptotic effects of prostaglandin analogues and blood flow regulation of carbonic anhydrase inhibitors [87]. This may infer that novel agents targeting similar pathways would not bring additional benefit.

Since glaucoma is typically a slowly progressing disease, a long period of observation is often required to assess therapeutic efficacy in a clinical trial $[88,89]$. Furthermore, damage to the optic nerve occurs before clinically measurable changes in visual fields, with up to $20-40 \%$ of RGCs are lost before visual field defects are detected [90]. However, strategies for assessing rates of progression of visual fields and OCT imaging are increasingly advocated to reduce the length of clinical trials [91-93]. Novel techniques such as DARC (Detection of Apoptosing Retinal Cells) have been developed as biomarkers [94] in the hope of more accurately quantifying drug efficacy by disease activity, especially in the early stages, and indeed has been utilised for this purpose experimentally, testing neuroprotective drugs including topical curcumin, topical Coenzyme Q10, glutamate modulation, and stem cell transplantation [27, 29, 43, 95-97]. With clinical trials showing promising results, $[98,99]$ it is hoped that DARC can be used as a surrogate endpoint in clinical trials for novel neuroprotective strategies.

\section{Conclusions}

Currently, there are a number of different neuroprotective strategies that have reached clinical trials but there are many and common limitations to evidence in this field of research. The difficulty in clinical translation is that many drugs, despite having positive results from preclinical data, failed to pass phase II clinical trials [6]. This may be attributed to the complex and as yet incompletely understood pathogenesis of disease, in addition to its slow progression requiring long term followup for clinically detectable changes to occur with current methodologies. Alternative trial designs for clinical trials may be beneficial to close the translation gap. An adaptive trial design increases flexibility and efficacy, providing the opportunity to modify the trial with prespecified criteria [99]. Another potential design is a futility trial design which tests the non-superiority of the intervention and removes unfavourable treatment with fewer subjects and in a shorter study period. It is important to adopt emerging highly sensitive biomarkers, have better visual field testing protocols, and have tight control for confounding factors. There may be an argument for treating at a much earlier disease stage when RGCs are believed to be less vulnerable and perhaps more amenable to neuroprotection [100]. Future clinical trials need to focus on the preservation of vision in patients. The detection of early glaucoma with novel biomarkers is the first stage in the future of diagnosis and treatment of glaucoma. Additionally, the development of tools enabling the objective measurement of neuroprotection outcomes is required. Hopefully, future researchers will take on board lessons learnt from previous trials' experiences to maximise the chances of providing new sight-saving therapies for our patients. 


\section{Author Contributions}

CF drafted and constructed the manuscript, carried out the literature review and summarization of studies. $L G$ and DH validated the studies and provided the main revisions. TY contributed critical revision and editing of the manuscript. MFC conceptualized the paper, completed final revisions and oversaw the research.

\section{Competing Interests}

Professor M. Francesca Cordeiro is a named inventor on a patent application covering the DARC technology disclosed in this manuscript. The remaining authors declare no conflict of interest.

\section{References}

1. Levin LA, Crowe ME, Quigley HA, Cordeiro MF, Donoso LA, Liao YJ, et al. Neuroprotection for glaucoma: Requirements for clinical translation. Exp Eye Res. 2017; 157: 34-37.

2. Baker M. 1,500 scientists lift the lid on reproducibility. Nature. 2016; 533: 452-454.

3. Nucci C, Martucci A, Giannini C, Morrone LA, Bagetta G, Mancino R. Neuroprotective agents in the management of glaucoma. Eye. 2018; 32: 938-945.

4. Guymer C, Wood JP, Chidlow G, Casson RJ. Neuroprotection in glaucoma: Recent advances and clinical translation. Clin Exp Ophthalmol. 2018.

5. Yu D-Y, Cringle SJ, Balaratnasingam C, Morgan WH, Yu PK, Su E-N. Retinal ganglion cells: Energetics, compartmentation, axonal transport, cytoskeletons and vulnerability. Prog Retin Eye Res. 2013; 36: 217-246.

6. Almasieh M, Levin LA. Neuroprotection in glaucoma: Animal models and clinical trials. Annu Rev Vis Sci. 2017; 3: 91-120.

7. Osborne NN. Mitochondria: Their role in ganglion cell death and survival in primary open angle glaucoma. Exp Eye Res. 2010; 90: 750-757.

8. Lee S, Van Bergen NJ, Kong GY, Chrysostomou V, Waugh HS, O'Neill EC, et al. Mitochondrial dysfunction in glaucoma and emerging bioenergetic therapies. Exp Eye Res. 2011; 93: 204-212.

9. Chrysostomou V, Rezania F, Trounce IA, Crowston JG. Oxidative stress and mitochondrial dysfunction in glaucoma. Curr Opin Pharmacol. 2013; 13: 12-15.

10. Raff MC, Barres BA, Burne JF, Coles HS, Ishizaki Y, Jacobson MD. Programmed cell death and the control of cell survival: Lessons from the nervous system. Science. 1993; 262: 695-700.

11. Johnson EC, Guo Y, Cepurna WO, Morrison JC. Neurotrophin roles in retinal ganglion cell survival: lessons from rat glaucoma models. Exp Eye Res. 2009; 88: 808-815.

12. Sena DF, Lindsley K. Neuroprotection for treatment of glaucoma in adults. Cochrane Database Syst Rev. 2017; CD006539.

13. Almasieh M, Wilson AM, Morquette B, Cueva Vargas JL, Di Polo A. The molecular basis of retinal ganglion cell death in glaucoma. Prog Retin Eye Res. 2012; 31: 152-181.

14. Feng L, Chen H, Yi J, Troy JB, Zhang HF, Liu X. Long-term protection of retinal ganglion cells and visual function by brain-derived neurotrophic factor in mice with ocular hypertension. Invest Ophth Vis Sci. 2016; 57: 3793-3802.

15. Mysona BA, Zhao J, Bollinger KE. Role of BDNF/TrkB pathway in the visual system: Therapeutic implications for glaucoma. Expert Rev Ophthalmol. 2017; 12: 69-81. 
16. Wang $\mathrm{H}$, Wang R, Thrimawithana $\mathrm{T}$, Little PJ, Xu J, Feng Z-P, et al. The nerve growth factor signaling and its potential as therapeutic target for glaucoma. Biomed Res Int. 2014; 2014: 759473-759473.

17. Colafrancesco V, Parisi V, Sposato V, Rossi S, Russo MA, Coassin M, et al. Ocular application of nerve growth factor protects degenerating retinal ganglion cells in a rat model of glaucoma. J Glaucoma. 2011; 20: 100-108.

18. Lambiase A, Aloe L, Centofanti M, Parisi V, Báo SN, Mantelli F, et al. Experimental and clinical evidence of neuroprotection by nerve growth factor eye drops: Implications for glaucoma. $P$ Natl Acad Sci USA. 2009; 106: 13469-13474.

19. Pease ME, Zack DJ, Berlinicke C, Bloom K, Cone F, Wang $Y$, et al. Effect of CNTF on retinal ganglion cell survival in experimental glaucoma. Invest Ophth Vis Sci. 2009; 50: 2194-2200.

20. Oddone F, Roberti G, Micera A, Busanello A, Bonini S, Quaranta L, et al. Exploring serum levels of brain derived neurotrophic factor and nerve growth factor across glaucoma stages. PLoS One. 2017; 12: e0168565.

21. Eckert A. Stabilization of mitochondrial membrane potential and improvement of neuronal energy metabolism by Ginkgo biloba extract EGb 761. Ann Ny Acad Sci. 2005; 1056: 474-485.

22. Hirooka K, Tokuda M, Miyamoto O, Itano T, Baba T, Shiraga F. The ginkgo biloba extract (EGb 761) provides a neuroprotective effect on retinal ganglion cells in a rat model of chronic glaucoma. Curr Eye Res. 2004; 28: 153-157.

23. Park JW, Kwon HJ, Chung WS, Kim CY, Seong GJ. Short-term effects of ginkgo biloba extract on peripapillary retinal blood flow in normal tension glaucoma. Korean J Ophthalmol. 2011; 25: 323.

24. Lee J, Sohn SW, Kee C. Effect of ginkgo biloba extract on visual field progression in normal tension glaucoma. J Glaucoma. 2013; 22: 780-784.

25. Shim SH, Kim JM, Choi CY, Kim CY, Park KH. Ginkgo biloba extract and bilberry anthocyanins improve visual function in patients with normal tension glaucoma. J Med Food. 2012; 15: 818823.

26. Quaranta L, Bettelli S, Uva MG, Semeraro F, Turano R, Gandolfo E. Effect of Ginkgo biloba extract on preexisting visual field damage in normal tension glaucoma. Ophthalmology. 2003; 110: 359-364.

27. Guo X, Kong X, Huang R, Jin L, Ding X, He M, et al. Effect of Ginkgo biloba on visual field and contrast sensitivity in Chinese patients with normal tension glaucoma: A randomized, crossover clinical trial. Invest Ophth Vis Sci. 2014; 55: 110-116.

28. ClinicalTrials.gov. Impact of Oral Versatile Antioxidants on Glaucoma Progression. 2012.

Available from:

https://clinicaltrials.gov/ct2/show/NCT01544192?term=neuroprotection\&cond=Glaucoma\&d raw $=1 \&$ rank=11.

29. Davis BM, Tian K, Pahlitzsch M, Brenton J, Ravindran N, Butt G, et al. Topical Coenzyme Q10 demonstrates mitochondrial-mediated neuroprotection in a rodent model of ocular hypertension. Mitochondrion. 2017; 36: 114-123.

30. Parisi V, Centofanti M, Gandolfi S, Marangoni D, Rossetti L, Tanga L, et al. Effects of coenzyme Q10 in conjunction with vitamin E on retinal-evoked and cortical-evoked responses in patients with open-angle glaucoma. J Glaucoma. 2014; 23: 391-404. 
31. Quaranta L, Riva I, Biagioli E, Rulli E, Rulli E, Poli D, et al. Evaluating the effects of an ophthalmic solution of coenzyme Q10 and vitamin E in open-angle glaucoma patients: A study protocol. Adv Ther. 2019; 2506-2514.

32. Kalogerou M, Kolovos P, Prokopiou E, Papagregoriou G, Deltas C, Malas S, et al. Omega-3 fatty acids protect retinal neurons in the DBA/2J hereditary glaucoma mouse model. Exp Eye Res. 2018; 167: 128-139.

33. Nguyen CTO, Bui BV, Sinclair AJ, Vingrys AJ. Dietary omega 3 fatty acids decrease intraocular pressure with age by increasing aqueous outflow. Invest Ophth Vis Sci. 2007; 48: 756-762.

34. Renard J-P, Rouland J-F, Bron A, Sellem E, Nordmann J-P, Baudouin C, et al. Nutritional, lifestyle and environmental factors in ocular hypertension and primary open-angle glaucoma: An exploratory case-control study. Acta Ophthalmol. 2013; 91: 505-513.

35. Kang JH, Pasquale LR, Willett WC, Rosner BA, Egan KM, Faberowski N, et al. Dietary fat consumption and primary open-angle glaucoma. Am J Clin Nutr. 2004; 79: 755-764.

36. Downie LE, Vingrys AJ. Oral Omega-3 supplementation lowers intraocular pressure in normotensive adults. Transl Vis Sci Technol. 2018; 7: 1-1.

37. Garcia-Medina JJ, Garcia-Medina M, Garrido-Fernandez P, Galvan-Espinosa J, Garcia-Maturana C, Zanon-Moreno V, et al. A two-year follow-up of oral antioxidant supplementation in primary open-angle glaucoma: an open-label, randomized, controlled trial. Acta Ophthalmol. 2015; 93: 546-554.

38. Folch J, Busquets O, Ettcheto M, Sanchez-Lopez E, Castro-Torres RD, Verdaguer E, et al. Memantine for the treatment of dementia: A review on its current and future applications. J Alzheimers Dis. 2018; 62: 1223-1240.

39. Hare WA, Wheeler L. Experimental glutamatergic excitotoxicity in rabbit retinal ganglion cells: block by memantine. Invest Ophth Vis Sci. 2009; 50: 2940-2948.

40. Ju WK, Kim KY, Angert M, Duong-Polk KX, Lindsey JD, Ellisman MH, et al. Memantine blocks mitochondrial OPA1 and cytochrome $c$ release and subsequent apoptotic cell death in glaucomatous retina. Invest Ophth Vis Sci. 2009; 50: 707-716.

41. Sánchez-López E, Egea MA, Davis BM, Guo L, Espina M, Silva AM, et al. Memantine-loaded pegylated biodegradable nanoparticles for the treatment of glaucoma. Small. 2018; 14: 1701808.

42. Guo L, Salt TE, Luong V, Wood N, Cheung W, Maass A, et al. Targeting amyloid-beta in glaucoma treatment. P Natl Acad Sci USA. 2007; 104: 13444-13449.

43. Guo L, Salt TE, Maass A, Luong V, Moss SE, Fitzke FW, et al. Assessment of neuroprotective effects of glutamate modulation on glaucoma-related retinal ganglion cell apoptosis in vivo. Invest Ophth Vis Sci. 2006; 47: 626-633.

44. Weinreb RN, Liebmann JM, Cioffi GA, Goldberg I, Brandt JD, Johnson CA, et al. Oral memantine for the treatment of glaucoma: Design and results of 2 randomized, placebo-controlled, phase 3 studies. Ophthalmology. 2018; 125: 1874-1885.

45. Oh DJ, Chen JL, Vajaranant TS, Dikopf MS. Brimonidine tartrate for the treatment of glaucoma. Expert Opin Pharmacother. 2019; 20: 115-122.

46. Nizari S, Guo L, Davis BM, Normando EM, Galvao J, Turner LA, et al. Non-amyloidogenic effects of $\alpha 2$ adrenergic agonists: Implications for brimonidine-mediated neuroprotection. Cell Death Dis. 2016; 7: e2514-e2514. 
47. Zhou X, Zhang T, Wu J. Brimonidine enhances inhibitory postsynaptic activity of OFF- and ONtype retinal ganglion cells in a Wistar rat chronic glaucoma model. Exp Eye Res. 2019; 189: 107833-107833.

48. Jung KI, Kim JH, Park CK. $\alpha 2$-Adrenergic modulation of the glutamate receptor and transporter function in a chronic ocular hypertension model. Eur J Pharmacol. 2015; 765: 274-283.

49. Tsai JC, Chang HW. Comparison of the effects of brimonidine $0.2 \%$ and timolol $0.5 \%$ on retinal nerve fiber layer thickness in ocular hypertensive patients: A prospective, unmasked study. J Ocul Pharmacol Ther. 2005; 21: 475-482.

50. Evans DW, Hosking SL, Gherghel D, Bartlett JD. Contrast sensitivity improves after brimonidine therapy in primary open angle glaucoma: A case for neuroprotection. Br J Ophthalmol. 2003; 87: 1463-1465.

51. Gandolfi SA SC, Cimino L. Is there a non IOP-related effect of brimonidine on visual field progression in human glaucoma? Invest Ophth Vis Sci. 2004; 45: 2298-2298.

52. Krupin T, Liebmann JM, Greenfield DS, Ritch R, Gardiner S, Low-Pressure Glaucoma Study Group. A randomized trial of brimonidine versus timolol in preserving visual function: Results from the Low-Pressure Glaucoma Treatment Study. Am J Ophthalmol. 2011; 151: 671-681.

53. Krupin T. Special considerations in low-tension glaucoma. Can J Ophthalmol. 2007; 42: 414-417.

54. Cordeiro MF, Levin LA. Clinical evidence for neuroprotection in glaucoma. Am J Ophthalmol. 2011; 152: 715-716.

55. Aung T, Oen FTS, Wong HT, Chan YH, Khoo BK, Liu YP, et al. Randomised controlled trial comparing the effect of brimonidine and timolol on visual field loss after acute primary angle closure. Br J Ophthalmol. 2004; 88: 88-94.

56. Park CH, Kim YS, Noh HS, Cheon EW, Yang YA, Yoo JM, et al. Neuroprotective effect of citicoline against KA-induced neurotoxicity in the rat retina. Exp Eye Res. 2005; 81: 350-358.

57. Rejdak R, Toczołowski J, Solski J, Duma D, Grieb P. Citicoline treatment increases retinal dopamine content in rabbits. Ophthal Res. 2002; 34: 146-149.

58. Schuettauf F, Rejdak R, Thaler S, Bolz S, Lehaci C, Mankowska A, et al. Citicoline and lithium rescue retinal ganglion cells following partial optic nerve crush in the rat. Exp Eye Res. 2006; 83: 1128-1134.

59. Park CH, Kim YS, Cheon EW, Noh HS, Cho CH, Chung IY, et al. Action of citicoline on rat retinal expression of extracellular-signal-regulated kinase (ERK1/2). Brain Res. 2006; 1081: 203-210.

60. Oshitari T, Fujimoto N, Adachi-Usami E. Citicoline has a protective effect on damaged retinal ganglion cells in mouse culture retina. Neuroreport. 2002; 13: 2109-2111.

61. Pecori Giraldi J, Virno M, Covelli G, Grechi G, De Gregorio F. Therapeutic value of citicoline in the treatment of glaucoma (computerized and automated perimetric investigation). Int Ophthalmol. 1989; 13: 109-112.

62. Virno M, Pecori-Giraldi J, Liguori A, De Gregorio F. The protective effect of citicoline on the progression of the perimetric defects in glaucomatous patients (perimetric study with a 10-year follow-up). Acta Ophthalmol Scan. 2000: 56-57.

63. Rejdak R, Toczołowski J, Kurkowski J, Kamiński ML, Rejdak K, Stelmasiak Z, et al. Oral citicoline treatment improves visual pathway function in glaucoma. Med Sci Monit. 2003; 9: PI24-PI28.

64. Ottobelli L, Manni GL, Centofanti M, lester M, Allevena F, Rossetti L. Citicoline oral solution in glaucoma: Is there a role in slowing disease progression? Ophthalmologica. 2013; 229: 219-226. 
65. Roberti G, Tanga L, Parisi V, Sampalmieri M, Centofanti M, Manni G. A preliminary study of the neuroprotective role of citicoline eye drops in glaucomatous optic neuropathy. Indian J Ophthalmol. 2014; 62: 549-553.

66. Parisi V, Centofanti M, Ziccardi L, Tanga L, Michelessi M, Roberti G, et al. Treatment with citicoline eye drops enhances retinal function and neural conduction along the visual pathways in open angle glaucoma. Graefes Arch Clin Exp Ophthalmol. 2015; 253: 1327-1340.

67. Biermann J, Boyle J, Pielen A, Lagrèze WA. Histone deacetylase inhibitors sodium butyrate and valproic acid delay spontaneous cell death in purified rat retinal ganglion cells. Mol Vis. 2011; 17: 395-403.

68. Biermann J, Grieshaber P, Goebel U, Martin G, Thanos S, Di Giovanni S, et al. Valproic acidmediated neuroprotection and regeneration in injured retinal ganglion cells. Invest Ophth Vis Sci. 2010; 51: 526-534.

69. Zhang ZZ, Gong YY, Shi YH, Zhang W, Qin XH, Wu XW. Valproate promotes survival of retinal ganglion cells in a rat model of optic nerve crush. Neuroscience. 2012; 224: 282-293.

70. Iraha S, Hirami Y, Ota S, Sunagawa GA, Mandai M, Tanihara H, et al. Efficacy of valproic acid for retinitis pigmentosa patients: A pilot study. Clin Ophthalmol. 2016; 10: 1375-1384.

71. Mahalingam K, Chaurasia AK, Gowtham L, Gupta S, Somarajan BI, Velpandian T, et al. Therapeutic potential of valproic acid in advanced glaucoma: A pilot study. Indian J Ophthalmol. 2018; 66: 1104-1108.

72. Hains BC, Waxman SG. Neuroprotection by sodium channel blockade with phenytoin in an experimental model of glaucoma. Invest Ophth Vis Sci. 2005; 46: 4164-4169.

73. Becker B, Stamper RL, Asseff C, Podos SM. Effect of diphenylhydantoin on glaucomatous field loss: A preliminary report. Trans Am Acad Ophthalmol Otolaryngol. 1972; 76: 412-422.

74. Raftopoulos R, Hickman SJ, Toosy A, Sharrack B, Mallik S, Paling D, et al. Phenytoin for neuroprotection in patients with acute optic neuritis: A randomised, placebo-controlled, phase 2 trial. Lancet Neurol. 2016; 15: 259-269.

75. ClinicalTrials.gov. Clinical cohort study of association between steady state phenytoin treatment and better clinical parameters of glaucoma. 2008. Available from: https://clinicaltrials.gov/ct2/show/NCT00739154.

76. Versura P, Buzzi M, Giannaccare G, Terzi A, Fresina M, Velati C, et al. Targeting growth factor supply in keratopathy treatment: Comparison between maternal peripheral blood and cord blood as sources for the preparation of topical eye drops. Blood Transfus. 2016; 14: 145-151.

77. Versura P, Profazio V, Buzzi M, Stancari A, Arpinati M, Malavolta N, et al. Efficacy of standardized and quality-controlled cord blood serum eye drop therapy in the healing of severe corneal epithelial damage in dry eye. Cornea. 2013; 32: 412-418.

78. Yoon KC, Jeong IY, Im SK, Park YG, Kim HJ, Choi J. Therapeutic effect of umbilical cord serum eyedrops for the treatment of dry eye associated with graft-versus-host disease. Bone Marrow Transpl. 2007; 39: 231-235.

79. Campos E, Versura P, Giannaccare G, Terzi A, Bisti S, Di Marco S, et al. Topical treatment with cord blood serum in glaucoma patients: A preliminary report. Case Rep Ophthalmol Med. 2018; 2018: 1-6.

80. Wilkins A, Kemp K, Ginty M, Hares K, Mallam E, Scolding N. Human bone marrow-derived mesenchymal stem cells secrete brain-derived neurotrophic factor which promotes neuronal survival in vitro. Stem Cell Res. 2009; 3: 63-70. 
81. Johnson TV, Bull ND, Hunt DP, Marina N, Tomarev SI, Martin KR. Neuroprotective effects of intravitreal mesenchymal stem cell transplantation in experimental glaucoma. Invest Ophth Vis Sci. 2010; 51: 2051-2059.

82. Weiss JN, Levy S, Malkin A. Stem Cell Ophthalmology Treatment Study (SCOTS) for retinal and optic nerve diseases: A preliminary report. Neural Regen Res. 2015; 10: 982-988.

83. ClinicalTrials.gov. Effectiveness and Safety of Adipose-Derived Regenerative Cells for Treatment of Glaucomatous Neurodegeneration. 2014. Available from: https://clinicaltrials.gov/ct2/show/results/NCT02144103.

84. Yap TE, Balendra SI, Almonte MT, Cordeiro MF. Retinal correlates of neurological disorders. Ther Adv Chronic Dis. 2019; 10: 2040622319882205-2040622319882205.

85. Patel NB, Lim M, Gajjar A, Evans KB, Harwerth RS. Age-associated changes in the retinal nerve fiber layer and optic nerve head. Invest Ophthalmol Vis Sci. 2014; 55: 5134-5143.

86. Quigley HA. Clinical trials for glaucoma neuroprotection are not impossible. Curr Opin Ophthalmol. 2012; 23: 144-154.

87. Shih GC, Calkins DJ. Secondary neuroprotective effects of hypotensive drugs and potential mechanisms of action. Expert Rev Ophthalmol. 2012; 7: 161-175.

88. Smith CA, West ME, Sharpe GP, Hutchison DM, Shuba LM, Rafuse PE, et al. Asymmetry analysis of macular optical coherence tomography angiography in patients with glaucoma and healthy subjects. Br J Ophthalmol. 2020.

89. likawa R, Togano T, Sakaue Y, Suetake A, Igarashi R, Miyamoto D, et al. Estimation of the central 10-degree visual field using en-face images obtained by optical coherence tomography. PLoS One. 2020; 15: e0229867.

90. Kerrigan-Baumrind LA, Quigley HA, Pease ME, Kerrigan DF, Mitchell RS. Number of ganglion cells in glaucoma eyes compared with threshold visual field tests in the same persons. Invest Ophth Vis Sci. 2000; 41: 741-748.

91. Wu Z, Crabb DP, Chauhan BC, Crowston JG, Medeiros FA. Improving the feasibility of glaucoma clinical trials using trend-based visual field progression end points. Ophthalmol Glaucoma. 2019; 2: 72-77.

92. Garway-Heath DF, Crabb DP, Bunce C, Lascaratos G, Amalfitano F, Anand N, et al. Latanoprost for open-angle glaucoma (UKGTS): A randomised, multicentre, placebo-controlled trial. Lancet. 2015; 385: 1295-1304.

93. Hood DC. Improving our understanding, and detection, of glaucomatous damage: An approach based upon optical coherence tomography (OCT). Prog Retin Eye Res. 2017; 57: 46-75.

94. Cordeiro MF, Guo L, Luong V, Harding G, Wang W, Jones HE, et al. Real-time imaging of single nerve cell apoptosis in retinal neurodegeneration. P Natl Acad Sci USA. 2004; 101: 1335213356.

95. Guo L, Cordeiro MF. Assessment of neuroprotection in the retina with DARC. Prog Brain Res. 2008; 173: 437-450.

96. Yap T, Donna P, Almonte M, Cordeiro M. Real-time imaging of retinal ganglion cell apoptosis. Cells. 2018; 7: 60.

97. Davis BM, Pahlitzsch M, Guo L, Balendra S, Shah P, Ravindran N, et al. Topical curcumin nanocarriers are neuroprotective in eye disease. Sci Rep. 2018; 8: 1-13.

98. Yap TE SE, Guo L, Cordeiro MF. Ophthal res lecture 2018: DARC as a potential surrogate marker. Ophthalmic Res. 2020; 63: 1-7. 
99. Normando EM, Yap TE, Maddison J, Miodragovic S, Bonetti $\mathrm{P}$, Almonte $\mathrm{M}$, et al. A CNN-aided method to predict glaucoma progression using DARC (Detection of Apoptosing Retinal Cells). Expert Rev Mol Diagn. 2020; 1-12.

100. Bhatt DL, Mehta C. Adaptive designs for clinical trials. New Engl J Med. 2016; 375: 65-74.

101. Osborne NN. Recent clinical findings with memantine should not mean that the idea of neuroprotection in glaucoma is abandoned. Acta Ophthalmol. 2009; 87: 450-454.

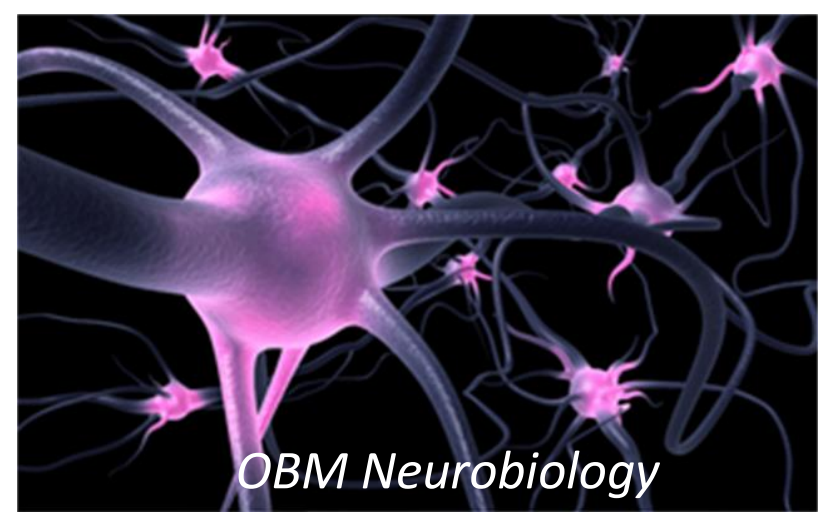

Enjoy OBM Neurobiology by:

1. Submitting a manuscript

2. Joining volunteer reviewer bank

3. Joining Editorial Board

4. Guest editing a special issue

For more details, please visit:

http://www.lidsen.com/journals/neurobiology 